\section{ITINERÁRIO TERAPÊUTICO E VIVÊNCIA DOS FAMILIARES E ADOLESCENTES COM DIABETES MELLITUS TIPO 1}

\author{
Therapeutic itinerary and experience of families and \\ adolescents with type 1 diabetes mellitus \\ Itinerario terapéutico y vivencia de los familiares y adolescentes \\ con diabetes mellitus tipo 1
}

\section{RESUMO}

Objetivo: Conhecer a vivência dos familiares e de adolescentes com diabetes mellitus tipo 1 (DM1) em relação à doença e ao itinerário terapêutico para a rede pública de saúde. Métodos: Pesquisa exploratória de natureza qualitativa, realizada nos meses de agosto a setembro de 2015. Os participantes foram dez adolescentes com diabetes mellitus tipo 1 e seus familiares que participavam diretamente dos cuidados em três Unidades de Saúde de Santa Catarina Brasil. Realizou-se entrevista aberta com adolescentes e familiares, bem como observação de campo. Os dados foram tratados por análise de conteúdo temática. A análise resultou na construção de três categorias: sentimentos manifestados após a descoberta da doença; conviver com diabetes mellitus tipo $1 \mathrm{e}$; a rede de atenção à saúde no acompanhamento da pessoa com DM1. Resultados: A descoberta da doença vem acompanhada de apreensão e requer mudanças na rotina de toda a família. O maior desafio refere-se à adequação dos hábitos alimentares. A aceitação da doença é dificultada pela condição da adolescência e a convivência com o diabetes é permeada de dúvidas quanto ao futuro. Na rede de atenção à saúde, as escolhas terapêuticas utilizadas pelas famílias e adolescentes estão centradas na atenção especializada. Conclusão: A constituição do itinerário terapêutico dos adolescentes e familiares é marcada pelo uso de variados recursos que extrapolam as fronteiras dos serviços de saúde, que devem preparar-se para apoiar as famílias que vivem com esta condição.

Descritores: Adolescente; Diabetes Mellitus; Doença Crônica; Saúde Pública.

\section{ABSTRACT}

Objective: To know the experience of families and adolescents with type 1 diabetes mellitus (DM1) regarding the disease and the therapeutic itinerary to the public health care system. Methods: Qualitative exploratory research conducted from August to September 2015. Participants were ten adolescents with type 1 diabetes mellitus and their family members who participated directly in their care in three Health Centers of Santa Catarina - Brazil. Open interviews were carried out with adolescents and their family members in addition to field observation. Data underwent thematic analysis. The analysis resulted in the construction of three categories: feelings experienced after the discovery of the disease; living with type 1 diabetes mellitus and; health care system in monitoring the person with DM1. Results: The discovery of the disease is accompanied by concern and requires changes in the routine of the whole family. The biggest challenge relates to adjusting eating habits. Acceptance of the disease is complicated by the adolescence condition and living with diabetes is riddled with doubts about the future. In the health care system, the therapeutic choices of families and adolescents are focused on specialized care. Conclusion: The constitution of the therapeutic itinerary of adolescents and family members is marked by the use of several resources that go beyond the boundaries of health services, which should be prepared to support families living with this condition.

Descriptors: Adolescent; Diabetes Mellitus; Chronic Disease; Public Health.
Artigo Original
1) Universidade Regional de Blumenau FURB - Blumenau (SC) - Brasil 


\section{RESUMEN}

Objetivo: Conocer la vivencia de los familiares y adolescentes con Diabetes Mellitus tipo 1 (DM1) respecto la enfermedad y el itinerario terapéutico de la red pública de salud. Métodos: Investigación exploratoria de naturaleza cualitativa realizada en los meses de agosto y septiembre de 2015. Los participantes fueron diez adolescentes con DM1 y sus familiares que participaban directamente de sus cuidados en tres Unidades de Salud de Santa Catarina-Brasil. Se realizó una entrevista abierta con adolescentes y familiares así como la observación de campo. Los datos fueron analizados a través del contenido temático. El análisis ha resultado en la construcción de tres categorías: sentimientos manifestados después del diagnóstico de la enfermedad; convivir con el DM1 y; la red de atención a la salud en el seguimiento de la persona con DM1. Resultados: El diagnóstico de la enfermedad se junta a la aprensión de la persona y requiere cambios de la rutina de toda la familia. El mayor desafio se refiere a la adecuación de los hábitos alimentarios. La aceptación de la enfermedad es más dificil debido la condición de la adolescencia y la convivencia con el diabetes es llena de dudas sobre el futuro. En la red de atención a la salud, las elecciones terapéuticas utilizadas por las familias y adolescentes están centradas en la atención especializada. Conclusión: El itinerario terapéutico de los adolescentes y familiares es marcado por el uso de varios recursos que ultrapasan las fronteras de los servicios de salud los cuales deben prepararse para apoyar a las familias que viven con esta condición.

Descriptores: Adolescente; Diabetes Mellitus; Enfermedad Crónica; Salud Pública.

\section{INTRODUÇÃO}

As condições crônicas se iniciam e evoluem lentamente. Usualmente apresentam múltiplas causas que variam no tempo, incluindo hereditariedade, estilos de vida, exposição a fatores ambientais e fatores fisiológicos ${ }^{(1)}$. O diabetes mellitus faz parte das doenças crônicas, não tem cura, mas é passível de controle dos níveis glicêmicos com vistas a evitar complicações e viver com qualidade. Isto requer mudanças no estilo de vida, especialmente adoção de uma alimentação saudável e da prática de atividade física associados ao tratamento medicamentoso ${ }^{(2)}$.

O Diabete Mellitus tipo 1 (DM1) é a segunda doença crônica mais frequente da infância, é responsável por $90 \%$ dos casos de diabetes na infância, no entanto, apenas $50 \%$ dos casos são diagnosticados antes dos $15 \operatorname{anos}^{(3)}$.

A adolescência é o período de transição entre a infância e vida adulta, abrange as idades de 10 a 19 $\operatorname{anos}^{(4)}$, caracterizado pelos impulsos do desenvolvimento físico, mental, emocional, sexual, social e pelos esforços do indivíduo em alcançar os objetivos relacionados às expectativas culturais da sociedade em que vive ${ }^{(5)}$. Ao descobrir-se com uma doença crônica, como o diabetes mellitus, a criança e ou adolescente tem seu comportamento modificado. Por sua vez, os familiares terão também que adequar-se a essa nova situação, e são muito importantes para o apoio e sucesso do tratamento do adolescente.

Considerando à condição crônica do adolescente com DM1 e a necessidade de práticas profissionais mais integrativas, torna-se relevante compreender a experiência de adoecimento e procura por atendimento, destacando o trajeto percorrido, possibilitando, assim, dar-lhes $\operatorname{respostas}^{(6)}$.

Conhecer o Itinerário Terapêutico-IT desses usuários em busca do tratamento do DM na rede básica de saúde, permite analisar as redes de sustentação e de apoio que são construídas por eles e família na experiência de adoecimento e busca pelo cuidado, evidenciando que novas redes vão se constituindo nos deslocamentos dessas pessoas ${ }^{(6)}$.

Por outro lado, as redes de atenção à saúde - RAS - devem configurar-se em desenhos institucionais nos diversos pontos da atenção à saúde e dos sistemas de apoio de forma equilibrada com critério de acesso aos serviços ${ }^{(7)}$.

$\mathrm{O}$ atendimento profissional desses adolescentes com DM1, na rede pública de saúde, onde as autoras trabalham é uma realidade. Por se tratar de uma fase de muitas transformações, ao descobrir o diagnóstico, inicia-se nova fase de adaptação e busca por atendimento pelos serviços disponíveis na rede pública.

A região do Médio Vale do Itajaí-MVI, em Santa Catarina - Brasil, possui extensa rede de Atenção Básica (AB) constituída por Unidades Básicas de Saúde - UBS - e unidades de Estratégia Saúde da Família - ESF -, as quais são responsáveis por acompanhar e ordenar o cuidado da população que vive em seus territórios, em qualquer ponto das RAS.

Percebe-se, ainda, pouca participação da atenção básica no atendimento destes adolescentes, sendo que a atenção secundária os assume e não compartilha o projeto terapêutico com a equipe da atenção básica. Os serviços se superpõem, muitas vezes caracterizando-se como disputa dos esforços para o cuidado e a não realização da atenção em rede. O adolescente com DM1 se vincula ao médico especialista e a família parece encontrar mais segurança frente à instabilidade no transcorrer da doença. Assim, o contato dessa família com a ESF, em relação ao acompanhamento desse paciente, pode limitar-se à entrega de insumos que necessita.

Diante das dificuldades enfrentadas pelos adolescentes e seus familiares ao descobrirem o DM1 e das diversas possibilidades de cuidado familiar e profissional, este estudo teve por pressupostos: Qual a vivência dos familiares e de adolescentes com diabetes mellitus tipo 1 (DM1) em relação à doença e ao itinerário terapêutico para a rede pública? 
Diante desse contexto, objetivou-se conhecer a vivência dos familiares e de adolescentes com diabetes mellitus tipo 1 (DM1) em relação à doença e ao itinerário terapêutico para a rede pública de saúde.

\section{MÉTODOS}

Este artigo é parte da pesquisa da dissertação de mestrado em saúde coletiva, de natureza qualitativa, exploratória.

A pesquisa foi realizada na Policlínica de Especialidade - PU - e no Núcleo de Apoio ao Diabético - NAD - da Secretaria Municipal de Saúde - SEMUS - de uma região do estado de Santa Catarina - Brasil e na Policlínica Universitária - PU - da Universidade Regional de Blumenau - FURB. Estes totalizam 100\% dos serviços que atendem exclusivamente a usuários do Sistema Único de Saúde SUS - e constituem-se a referência da atenção secundária para região do Médio Vale do Itajaí, com 78 crianças e adolescentes cadastrados.

Participaram da pesquisa dez adolescentes com DM1 e dez familiares envolvidos diretamente nos cuidados ao adolescente da região. Os critérios de inclusão foram: ser adolescente portador de DM1; idade de 12 a 17 anos; ser atendido por um dos serviços de referência da região; ter diagnóstico de DM1 estabelecido há pelo menos um ano; aceitar participar da pesquisa.

Os adolescentes e familiares foram convidados pela pesquisadora na sala de espera, enquanto aguardavam a consulta médica agendada e por meio de contato telefônico, a partir da listagem dos adolescentes cadastrados nos serviços, devido à baixa assiduidade na consulta médica. As entrevistas foram realizadas nos serviços (seis) e no domicílio (quatro) por escolha dos participantes.

Foram excluídos todos os adolescentes que não eram portadores de DM1; que tinham menos de 12 ou mais de 18 anos; que não eram atendidos por um dos serviços de referência da região; que tinham o diagnóstico estabelecido há menos de 1 ano; que não aceitaram participar do estudo; que não tinham tempo e disponibilidade para participar da pesquisa.

A partir da sétima entrevista ocorreu a saturação dos dados, o que se confirmou até a décima entrevista, optandose pela finalização da amostra.

Realizou-se uma entrevista aberta com cada familiar e adolescente, bem como observação de campo, vinculadas à consulta médica ou no domicílio, de agosto a setembro de 2015, pela pesquisadora responsável. A entrevista continha dados de identificação, com as variáveis (sexo, idade, cidade de origem, tempo de diagnóstico, parentesco do entrevistado e serviço de referência utilizado).
Todas as entrevistas foram gravadas na íntegra, com as perguntas norteadoras: Conte o que você sentiu quando descobriu que tem essa doença ou seu filho?- Conte como você tem vivenciado o diabetes após descobrir que você/seu filho(a) tem a doença? Como tem sido o caminho seguido desde a descoberta da doença até o local do tratamento?

As observações de campo como postura, expressões de alegria, tristeza ou de angústia, foram anotadas na ficha de observação, logo após cada entrevista. A transcrição das entrevistas foi feita pela pesquisadora no dia da coleta e no dia seguinte com a finalidade de manter a fidedignidade e abrangência das falas.

Para o tratamento dos dados, procedeu-se a análise de conteúdo $^{(8)}$. Cada entrevistado foi identificado pela letra $\mathrm{E}$ e um número sequencial até E10. O adolescente foi identificado pela letra A1 sucessivamente até A10. Definiuse na ordem sequencial E8, E8ô e E8ó, para o pai, avô e avó respectivamente. Após sucessivas leituras das entrevistas, realizou-se a organização do material atendendo os procedimentos metodológicos da análise de conteúdo utilizados a partir da perspectiva qualitativa, seguindo os seguintes passos: categorização, inferência, descrição e interpretação. Não ocorrendo necessariamente de forma sequencial ${ }^{(9)}$.

As categorias que emergiram do estudo foram: sentimentos manifestados após a descoberta da doença; conviver com diabetes mellitus tipo $1 \mathrm{e}$; a rede de atenção à saúde no acompanhamento da pessoa com DM1.

O projeto foi aprovado pelo Comitê de Ética da FURB com parecer $n^{\circ}$. 1.124.736. A coleta dos dados iniciou após esclarecimento dos objetivos da pesquisa, garantia do anonimato, permitindo esclarecimento de dúvidas e após o aceite com assinatura do Termo de Consentimento Livre e Esclarecido.

\section{RESULTADOS E DISCUSSÃO}

Nos resultados e análise da pesquisa serão discutidos os dados de identificação dos adolescentes e grau de parentescos dos familiares, seguem apresentadas as categorias que emergiram do estudo.

\section{Dados de identificação dos adolescentes}

Os adolescentes participantes do estudo foram em sua maioria do sexo feminino, sete; e do sexo masculino três. Eles tinham entre 12 e 15 anos de idade, oito deles residiam em Blumenau, um em Pomerode e um em Benedito Novo. O tempo de diagnóstico variou entre dois a 13 anos, sendo que seis deles eram acompanhados na PU-FURB, três no NAD e um na PU-SEMUS. Os familiares participantes do estudo foram quatro mães, três pais, uma madrasta, um irmão e houve uma entrevista coletiva pai, avó e avô. 


\section{Sentimentos manifestados após a descoberta da doença}

Essa categoria descreve os sentimentos manifestados após a descoberta da doença pelo adolescente e seus familiares. A descoberta da doença, para a maioria dos entrevistados, ocorreu de forma inesperada, como surpresa ou susto e, para muitos, significou uma nova demanda por cuidado fazendo com que o familiar tenha que abdicar de tempo para si, provocando até alteração na rotina de trabalho, como referido a seguir:

"Na verdade a descoberta do diagnóstico foi uma surpresa [...], inesperada." (A3)

"Bem ruim! A gente vive só em função dele a gente não vive mais para nós, só em função dele[...]. Para nós fica dificil. "(E9)

"Eu tive que mudar meu horário de trabalho e tudo [...] Eu tive que mudar toda rotina do serviço, tudo. [...] Eu trabalhava de manhã no primeiro turno, agora eu trabalho a noite."(E9)

Esta renúncia de si pode suspender atividades dos pais que envolvem o trabalho, escola, lazer e as relações com a família mantendo-os, a maior parte do tempo, na expectativa quanto às necessidades de saúde impostas pela doença crônica dos adolescentes, situação encontrada também nas famílias que tem filhos com anemia falciforme ${ }^{(10)}$.

A forma como está organizado o trabalho é fundamental para permitir adequações a fim de cuidar dos filhos ${ }^{(10)}$. A mudança não vem somente no horário de trabalho, mas nos ajustes financeiros que a família tem que reestruturar.

A suspeita do diagnóstico foi identificada pelos familiares e adolescentes de diversas formas, principalmente pelos sinais e sintomas divulgados pelos serviços de saúde e pela mídia, como o cheiro de acidose, a perda de peso, polidipsia, poliúria, cansaço e sudorese, presente nos depoimentos:

"Eu estava há uns 15 dias me sentindo muito cansada e com dor nas pernas e minha mãe sentiu meu hálito com cheiro de maçã " (A1)

"A minha mulher percebeu que ele estava indo muito no banheiro, tomando muita água, dai ela ficou meio desconfiada e mandou fazer um exame, o exame já acusou diabetes"(E9)

A partir da identificação dos sinais e sintomas já sugestivos de diabetes para a maior parte das pessoas portadoras de diabetes, a família recorre aos serviços de saúde em busca de tratamento. Em relação ao diagnóstico, a maioria foi confirmada na atenção básica, outros, em consultórios privados, convênio de saúde ou no hospital:
"No posto de saúde [...]. Assim que eu falei da sede ele (o médico) pegou o glicosímetro, fez o teste e deu quinhentos е роисо." (A3)

"Eu levei no pediatra que acompanhava ela desde neném. Ele desconfiou, e mandou fazer os exames e ela já estava assim, praticamente ia entrar em coma de tão alta que estava à glicemia. "(E5)

Pôde-se perceber a emoção, apreensão e medo quando falavam sobre o momento transcorrido entre a suspeita e a confirmação do diagnóstico, parecendo que tinham lhes tirado o chão. Ao confirmar o diagnóstico de diabetes, a família sofre um grande impacto e iniciam muitas preocupações ${ }^{(11)}$.

A informação adquirida por meio dos cartazes expostos na unidade de saúde auxiliou uma das mães na suspeita do diagnóstico:

"Eu sempre vou no postinho, lá eu sempre leio os cartazes [...] eu comentei com todo mundo aqui em casa que eu achava que ele estava com diabetes porque eu via lá no postinho aqueles cartazes falando dos sintomas do diabetes."(E7)

A informação visual disponibilizada pela equipe auxiliou essa mãe na suspeita da doença que se confirmou. Identificou-se a potencialidade da educação em saúde como uma ferramenta bastante utilizada pelos profissionais na sala de espera, visto que os usuários enquanto aguardam atendimento, podem realizar a leitura do material exposto nos murais. O conhecimento sobre si mesmo e do processo saúde-doença contribui para a mudança e adoção de novos hábitos ${ }^{(12)}$.

Para uma das mães a suspeita inicial era de que sua filha estava tentando emagrecer por estar na fase de adolescência e não aceitar seu peso:

"Ela começou a emagrecer, perdeu mais de 20 quilos, $e$ começou a secar [...]. Ela tinha muita sede e muito sono, dai eu pensei até que ela estava tendo aquele negócio de emagrecer sabe, daquelas meninas assim que são gordinhas e querem emagrecer [...]." (E6)

A mãe relacionou a perda de peso da filha com valores estéticos, morais, culturais e o controle do corpo exigido pela sociedade contemporânea, o que pode ter atrasado o diagnóstico. O culto da boa forma imposto socialmente vem associado à saúde em oposição à obesidade estigmatizada como mórbida ${ }^{(13)}$. Além de que os adolescentes são muitas vezes considerados um grupo de risco nutricional em razão de hábitos alimentares inadequados ${ }^{(14)}$.

O sentimento, a ansiedade e o saber de um participante que levou sua neta na unidade básica de saúde, explicitando 
sua suspeita de diabetes, foi desconsiderado pelo médico, protelando o diagnóstico e fazendo a família buscar outro serviço que acolheu e investigou a queixa, confirmando DM1.

Estudos apontam que experiências de adoecimentos são deslegitimadas pela medicina quando não comprovadas por diagnósticos médicos ${ }^{(13)}$. Neste caso, nem a queixa foi valorizada e investigada a fim de explicar e significar os sinais e sintomas percebidos pelo avô. A família que procurou a unidade básica de saúde, porta preferencial do Sistema Único de Saúde-SUS, teve que bater na porta do serviço de referência para ser escutada. Evidencia-se uma ruptura na trajetória institucional percorrida pela família provocada inicialmente, pelo médico que não acolheu e, posteriormente, a solução de continuidade na RAS se concretiza à medida que a atenção secundária não se comunica com a equipe da atenção primária a qual a família é adstrita.

As práticas que os profissionais de saúde desempenham desde a descoberta da doença, na vivência diária e nas fases futuras são fundamentais para as famílias e adolescentes, pois estes estarão sempre presente, seja na atenção básica, secundária ou terciária.

As famílias buscam os serviços de saúde que melhor acolham e atendam às suas necessidades. Porém, a decisão de permanecer em um serviço para o tratamento do diabetes parece estar relacionada ao vínculo da família com o médico.

"Ela era médica de diabetes pelo plano [...] Ele (o filho) não gostava muito dela" (E9)

"[...] Só teve aquele probleminha lá [Furb], a gente até gostava dela, quando a gente veio para cá, aqui (NAD) é mais especifico, achamos melhor ficar aqui. " (E1)

\section{O conviver com diabete mellitus tipo 1}

Após os sentimentos causados pelo impacto da descoberta da doença, o adolescente e suas famílias necessitaram realizar ajustes familiares para a nova realidade que foi o conviver com o diabetes mellitus tipo 1 , o tema desta categoria.

A aceitação da doença diabetes é um grande desafio para pais e adolescentes, mas encarar a nova realidade e se adaptar às muitas mudanças são inevitáveis, como mostram as falas:

\footnotetext{
"Sim, eu fiquei internada porque eu estava no último da diabetes, estava com $600 \mathrm{mg} / \mathrm{dl}$. Dai a psicóloga vinha falar comigo, um monte de gente vinha falar comigo, para me explicar o que era o diabetes, [...], mesmo assim, eu não entendia. Eu fiquei uns tempos lá para entrar na minha cabeça o que era o diabetes, mas até hoje não entrou, sabe. "(A2)
}

A aceitação da doença necessita de tempo e suporte de profissionais de saúde, familiares, amigos e da escola. É fundamental a pessoa e seus familiares receberem informações de seu estado de saúde de forma clara e no momento certo $^{(11)}$.

Para o adolescente entender e aceitar que o diabetes estará presente em toda sua vida é algo difícil, mesmo quando o diagnóstico ocorre na infância. Quando ele atinge a fase da adolescência inicia o momento da negação. Neste período de muitas transformações, há necessidade de suporte multiprofissional e da atenção em rede. Pois, a adolescência já é uma fase de muitas transformações físicas, mental, emocional, sexual e social ${ }^{(5)}$. E juntamente com os questionamentos da doença, vem a necessidade de realizar o controle da glicemia, fazendo testes e aplicando a insulina, gerando sofrimento nos pais e filhos:

"Pensa, todo dia tem que arrumar insulina, agora ele aplica sozinho, antes eu aplicava. Também não foi fácil para mim, eu não sou enfermeira, eu nunca lidei com agulha. Pensa a situação dele de manhã e de noite. Todo mundo fala, ah podia ser pior, cada um é cada um. " (E7)

Percebe-se o desespero dessa mãe frente à rotina diária de seu filho e muitas vezes os próprios profissionais direcionam mais as orientações à mãe, quando poderiam envolver todas as pessoas da família e o próprio adolescente.

Os médicos concebem a família, mais precisamente a mãe, o protagonismo da dor de seu filho e sobre essa concepção a mitificação da mãe, vista como heroína e de tal forma que a criança se torna "invisível", subestimando a concepção de mulher frente à grandeza da "missão" que cabe o papel de mãe $e^{(15)}$.

Muitos participantes associaram o surgimento do diabetes a fatos estressantes vivenciados pelos filhos.

"A doença dele surgiu depois que a mãe dele faleceu. E porque causa disso, o emocional da perda [...]. Ela teve câncer de mama, fez o tratamento e depois de cinco anos voltou com mais força e faleceu. " (E3)

Ficou clara a percepção dos familiares que o diabetes pode ser desencadeado por evento traumático. Autores afirmam que a interação de fatores genéticos, imunológicos e ambientais na etiologia diabetes do tipo 1 é um tema de constantes pesquisas ${ }^{(16)}$.

Os adolescentes encontram dificuldades para modificar sua rotina diária em função da doença e muitas vezes demonstram isso na forma de rebeldia:

"Está rebelde. [...] Ele está, como diz, de saco cheio. Dificil de lidar. [...]. Porque ele não era assim, de uns tempos para cá ele não quer ir nas consultas, não quer fazer o teste, ele às vezes fica revoltado, ele come um doce escondido. "(E7) 
Os depoimentos comprovaram que a fase de adolescência acaba por dificultar ainda mais aceitação da doença e os cuidados necessários para que se mantenha estável, por outro lado, o adolescente desejava ser igual a seus colegas, mas os cuidados que a doença impõe dificultam isso.

As restrições e limitações foram percebidas por pais e filhos como se fosse algo de punição, ordens a serem seguidas, porém em sua vida atual é um dever que não tem significado em sua experiência de adoecimento, mas se não seguir, poderá ter complicações futuramente ${ }^{(17)}$.

A convivência com o diabetes foi permeada de dúvidas e receio quanto ao futuro sobre a disponibilidade $\mathrm{e}$ possibilidade de acessar novas tecnologias para o tratamento e cura da doença, como referido:

"Às vezes eu tenho dúvida, o pâncreas dela não funciona, até onde não funciona? Onde que vai para conseguir um transplante de pâncreas? Isso é normal? Isso é fácil de conseguir? [...] Se um dia acontecer dela casar ela pode engravidar normal? [...] Ela vai precisar de uma cesárea?" (E10)

Constata-se que mesmo após anos da descoberta da doença, as famílias ainda têm muitas dúvidas, o que leva a questionar como têm sido realizados os atendimentos desses familiares. Tem se possibilitado momentos durante o atendimento dos profissionais de saúde para esclarecimento de dúvidas aos pacientes e aos familiares? Mais uma vez ressalta-se a importância de trabalho em rede de atenção e de equipe multiprofissional.

O desafio com alimentação foi relatado por todos os entrevistados sendo o que mais interfere na vivência da família, necessitando de adequações na dieta, muitas vezes vista como um sacrifício:

"A alimentação de todo mundo mudou junto comigo". (A1)

"Ai, controlar os doces. [...] eu gosto de doces, mas dai tem que controlar porque ela não pode, a gente tem que tentar maneirar. "(E5)

As falas citadas corroboram com o estudo ${ }^{(16)}$ que enfatiza a reestruturação do cardápio alimentar utilizado antes da descoberta do diabetes dos filhos e a adoção de novos hábitos, passando por uma educação de todo o grupo familiar.

As mudanças alimentares envolvendo toda família são fundamentais para o controle glicêmico dos adolescentes, tornando essa mudança para o adolescente menos dificultosa quando percebe que há o envolvimento da família neste processo.
Os familiares próximos como tios e avós compartilharam alguns cuidados em relação à alimentação quando recebem o adolescente em sua casa, como citado:

"Até quando a gente vai visitar a casa de alguém eles geralmente já preparam alguma coisa para ele comer. " (E3)

Este relato reforça a necessidade do envolvimento de todos os familiares de convívio direto ou indireto, que colaboram no cuidado do adolescente com DM1. Os profissionais de saúde têm papel essencial na troca de informações para auxiliar nesta demanda.

A participação da escola no controle alimentar dos adolescentes foi vista como fator positivo por vários entrevistados:

"Tem o lanche separado dela, na escola. A gente levou um papel lá, comunicou, dai eles já tem esses cuidados. "(E8)

"É que alimentação dele seria boa para os outros também. Melhor que aquelas porcarias de açúcar [...]." (E7)

Destaca-se aqui a preocupação e entendimento da E7, ao citar que a alimentação saudável para seu filho deveria ser igual para todos os alunos da escola. Acredita-se que essa mudança na preparação da alimentação escolar poderia promover uma vida mais saudável para todos os estudantes independente de existir ou não uma doença que demande este cuidado.

Ressalta-se que a educação em diabetes deve estar centrada na equipe multidisciplinar, no sistema familiar, no usuário e nos equipamentos sociais como escolas, com vistas a promover a aderência aos aspectos do tratamento além do medicamento ${ }^{(17)}$.

No entanto, para alguns participantes deste estudo, a convivência social com os amigos ou pessoas próximas nas questões alimentares foram vistas como fator dificultador:

"[...] o mais dificil é sair com os amigos, os amigos estão lá, tomam refrigerantes e ele para se controlar é dificil." (E9)

"Em casa ela até se controla, mas ela sai muito, dai na casa dos outros come um doce, em casa não tem doce [...] vai no posto de combustivel eles dão pirulito e não pode. […". (E4)

A falta de conhecimento ou preocupação das pessoas e amigos próximos acabou causando grande transtorno para os adolescentes e seus pais, desregulando o controle alimentar e podendo causar efeitos sérios nos níveis glicêmicos.

A maior dificuldade relatada pelos pais está relacionada com alimentação, por outro lado crianças e adolescentes 
com diabetes se sentem diferentes dos colegas devido às restrições alimentares ${ }^{(17)}$. A alimentação está relacionada à socialização em adultos também, estudos ${ }^{(12)}$ mostram que a adesão de hipertensos a dietas restritivas de sal e gordura é baixa porque contrariam os hábitos nos quais foram socializados.

Outro aspecto relatado pelos participantes da pesquisa, que dificulta a adoção de uma alimentação saudável foi o custo dos alimentos especiais para seus filhos:

"Tudo que é alimentação para diabético é mais caro. [...] absurdamente. Como que você vai tratar um doente se as coisas são mais caras que o normal? [...] se eles (o governo) pudessem baixar a parte de alimentação ajudava todo mundo. " (E9)

$\mathrm{O}$ alto custo para adquirir alimentos adequados aos portadores de DM1 acaba comprometendo o controle glicêmico dos adolescentes, pois se sabe que alimentação é um dos principais itens para se obter esse controle.

O custo dos alimentos novos e específicos para a patologia, a restrição alimentar aos filhos, justificam a dificuldade dos pais em relação à alimentação ${ }^{(17)}$.

Sobre qual dieta seria a adequada para o adolescente com diabetes, percebe-se duas concepções distintas. Primeiro, a alimentação saudável orientada para qualquer indivíduo pode ser consumida também pela pessoa com diabetes. Segundo, a alimentação para a pessoa com diabetes deve ser especial e majoritariamente constituída por produtos light e diet, sendo inclusive recomendada por muitos profissionais.

Um estudo mostrou que o conhecimento dos profissionais da Atenção Básica sobre a relação entre alimentação e diabetes ainda é permeado por confusões, notadamente no que se refere às diferenças entre produtos diet e light e a necessidade de recomendar o seu consumo para as pessoas com diabetes ${ }^{(18)}$.

Não obstante essas diferentes percepções, tanto os produtos diet e light quanto aqueles que devem compor uma alimentação considerada saudável, têm um custo financeiro elevado, dificultando a sua aquisição.

Salienta-se a necessidade de políticas públicas para estimular a comercialização de alimentos saudáveis, não somente aos portadores de diabetes, mas acessível às pessoas no cuidado da saúde, prevenindo assim o surgimento de doenças.

\section{A rede de atenção à saúde no acompanhamento da pessoa com DM1}

Nesta categoria são explorados os pontos da rede de atenção à saúde, atenção primária, secundária e terciária, no acompanhamento da pessoa com DM1, sempre em busca de melhor resolutividade.
Todos os entrevistados revelaram que diante da doença utilizam para tratamento e acompanhamento de seus filhos a atenção secundária, mantendo baixo vínculo com atenção básica, utilizando esta, em sua maioria, somente para acessar os insumos ofertados pelo SUS:

"No posto de saúde a gente pega as insulinas." (E9)

"Pega as fitas do aparelho." (A9)

"Dificil, às vezes, vai [no posto de saúde]. Mas, se levar certinho aqui o que ele manda fazer, já pega os exames, os remédios, as receitas, faz praticamente tudo aqui." (E1)

Outros autores ${ }^{(9)}$, também, constataram o fato da família possuir laços extremamente fracos com a unidade da ESF do bairro em que reside.

A ausência de trabalho em rede foi identificada tanto nos serviços do SUS quanto da rede privada, tornando-se um grande desafio ainda a ser enfrentado, contraindicando as recomendações do Ministério da Saúde que diz que a RAS deve atuar de forma articulada nos diversos níveis de atenção, com a finalidade de garantir a integralidade da assistência à saúde ${ }^{(19)}$.

A atenção prestada deve ser ordenada pelas unidades básicas de saúde, e com o apoio dos serviços de atenção secundária e terciária em rede, atuando equilibradamente sobre os determinantes sociais da saúde ${ }^{(1)}$. Para tanto, é imprescindível haver comunicação entre as equipes dos diferentes pontos da rede de atenção ao adolescente com diabetes.

Percebe-se que as relações construídas de forma estreita se deram através da relação médico com usuário e família, isto é, o usuário estava vinculado ao médico e não ao serviço, mesmo nos casos em que é cadastrado em uma unidade de saúde da família:

"Por telefone. Ele (o médico) é muito querido, muito atencioso. Passou e-mail e tudo. Se alguma dúvida que eu tenho, se eu não consigo falar com ele na hora, ele me liga de volta ou por e-mail." (E5)

No entanto, alguns sujeitos tiveram a assistência negada na $\mathrm{AB}$ ou ainda, baixa resolutividade na atenção especializada, caracterizando conflitos na relação com os serviços:

"Eu cheguei várias vezes bater na porta do postinho, ela estava entrando em coma e eles não atendiam ela." (E4)

"Eu fiquei consultando com ele (o médico), ele não conseguia normalizar minha glicose, ai resolveram encaminhar para a FURB." (A2)

A dificuldade com os serviços de saúde faz com que os familiares e usuários circulem na rede de atenção em busca daquele que melhor dê conta de suas necessidades e tratamento de seus filhos. Autores ${ }^{(20)}$ comentam que vários 
fatores contribuem para o acesso aos serviços de saúde, como fluxo adequado, resolutividade e qualidade.

Se, por um lado, é desejável que todo encontro entre cada profissional de saúde e usuário seja um espaço de manifestação de suas subjetividades e corresponsabilização na construção do projeto terapêutico, por outro lado, esta vinculação restrita ao médico limita muito as possibilidades de sucesso da terapia que, em diabetes, não pode prescindir da atuação interprofissional. Parece que, mesmo nos serviços nos quais o adolescente é atendido por outros profissionais, ainda predomina o modelo biomédico de atenção.

O bom relacionamento entre os profissionais de saúde com a pessoa com a doença e seus familiares é fundamental na orientação do cuidado.

Vários adolescentes relataram ter em algum momento de sua trajetória recebido atendimento de outros profissionais da saúde como nutricionistas, psicólogas e dentistas, e a possibilidade de marcar a consulta com os vários profissionais no mesmo período foi facilitador.

Com base nesses achados a integralidade da atenção voltada aos portadores de DM1 precisa ser posta em ação pelos profissionais de saúde em suas práticas de cuidado, pois dela depende a probabilidade de enfrentar essa experiência e aceitar outras formas de viver a vida ${ }^{(21)}$.

"Lá (PU/Furb) tem o médico [...], tem a nutricionista, a psicóloga, então a gente já faz tudo numa vez só”. (E8)

Esse relato corrobora que a compreensão e empatia da equipe multiprofissional que atende a família facilitará a adesão do adolescente com diabetes ao tratamento e sua integração na sociedade em que vive ${ }^{(11)}$. Além disso, os adolescentes que têm uma boa estrutura familiar têm mais condições de enfrentar o diabetes e controlar melhorar sua patologia, além de conseguirem que a doença tenha menor interferência em sua vida ${ }^{(22)}$.

A oferta de grupos educativos foi um mecanismo citado como uma ferramenta de apoio, orientação e esclarecimento de dúvidas:

"Ajudou bastante, a gente aprendeu muita coisa que não sabia, de alimentação, agora é claro, a gente pesquisa bastante na internet." (E7)

"[...] às vezes vem (no grupo educativo) nutricionista, psicóloga, o enfermeiro, ele conversa, sempre conversando sobre diabetes. " (A9)

Muitos profissionais vêm descobrindo a grande potencialidade da relação dialogada profunda com os usuários e grupos comunitários locais para a reorganização das práticas de assistência e promoção da saúde ${ }^{(12)}$.

Acredita-se que o envolvimento das pessoas no grupo pode estar influenciando positivamente na forma de compreender a informação ao possibilitar a troca de experiência entre os participantes.

\section{CONSIDERAÇÕES FINAIS}

Os resultados desta pesquisa possibilitaram conhecer a vivência dos familiares e de adolescentes com diabetes mellitus tipo 1 em relação à doença e ao itinerário terapêutico que utilizam a rede pública de saúde.

As falas revelaram com a descoberta da doença sentimentos como medo, ansiedade, sofrimento e incerteza quanto ao futuro, mas o maior desafio para adolescentes e familiares conviverem com o diabetes é adotar mudanças na alimentação.

A constituição do itinerário terapêutico dos adolescentes com diabetes e seus familiares é engendrada pela utilização de diversos recursos até encontrarem o que melhor se adapte e que os auxilie no tratamento e cuidado de seus filhos. Essa busca perpassou por consultórios privados, planos de saúde e serviços do Sistema Único de Saúde, caracterizando uma rede de diversificados caminhos e orientações.

As escolhas terapêuticas utilizadas pelas famílias e adolescentes estavam centradas na atenção secundária, com forte vínculo com o médico e, pontualmente, utilizam o suporte de outros profissionais como enfermeiro, nutricionista e psicólogo. A escuta dos sentimentos e saberes do usuário como "outro", diverso e legítimo deve ser incorporada às práticas dos profissionais como imperativo ético e técnico.

É premente a necessidade de implantação de uma política pública de atenção ao adolescente com DM1 em rede, na qual a atenção básica seja ordenadora da linha de cuidado, com protagonismo das equipes, trabalho interprofissional colaborativo e desenvolvimento de práticas que contribuam para a integralidade do cuidado.

\section{REFERÊNCIAS}

1. Mendes EV. O cuidado das condições crônicas na atenção primária à saúde: o imperativo da consolidação da estratégia da saúde da família. Brasília: Organização Pan-Americana da Saúde; 2012.

2. Ministério da Saúde (BR). Plano de ações estratégicas para o enfrentamento das doenças crônicas não transmissíveis (DCNT) no Brasil 20112022. Brasília: Ministério da Saúde; 2011 [acesso em 2015 Fev 12]. Disponível em: http://www. fnde.gov.br/arquivos/category/116-alimentacaoescolar?download=7897:plano-de-acoes-estrategicaspara-o-enfrentamento-das-dent-no-brasil

3. Sociedade Brasileira de Diabetes. Diretrizes da sociedade brasileira de diabetes 2014-2015. São Paulo: 
A.C. Farmacêutica; 2016 [acesso em 2015 Fev 12]. Disponível em: http://www.diabetes.org.br/diretrizese-posicionamentos.

4. OMS/OPS. La salud del adolescente y el joven em las Américas. In: Bianculli C, Blanca Andrada T, García Varela C, Barchetta C. Atención médica primaria de adolescentes en un hospital general de Buenos Aires, Argentina. Washington: OPS/OMS; 1985.

5. Eisenstein E. Adolescência: definições, conceitos e critérios. Rev Adolescência Saúde. 2005;2(2):6-7.

6. Bellato R, Araújo LFS, Castro P. O itinerário terapêutico como uma tecnologia avaliativa da integralidade em saúde. In: Pinheiro R, Silva AG Júnior, Mattos RA. Atenção básica e integralidade: contribuições para estudos de práticas avaliativas em saúde. Rio de Janeiro: Instituto de Medicina Social; 2011. p. 167-87.

7. Mendes EV. As redes de atenção à saúde: revisão bibliográfica, fundamentos, conceito e elementos constitutivos. Brasília: Organização Pan-americana da Saúde; 2011.

8. Bardin L. Análise de conteúdo. $3^{\mathrm{a}}$ ed. Lisboa: Edições 70; 2014.

9. Minayo MCS. Pesquisa social. Teoria, método de criatividade. $26^{\mathrm{a}}$ ed. Petrópolis: Vozes; 2007.

10. Silva AH, Bellato R, Araújo L. Cotidiano da família que experiência a condição crônica por anemia falciforme. Rev Eletrônica Enferm [Internet]. 2013 [acesso em 2015 Fev 10];15(2):437-46. Disponível em: http://revistas.jatai.ufg.br/index.php/fen/article/ view/17687.

11. Leal DT, Fialho FA, Andrade F, Dias IMAV, Nascimento L, Arruda WC. A vivência dos familiares de crianças e adolescentes portadores de diabetes mellitus tipo 1. Rev Eletrônica Enferm [Internet]. 2012 [acesso em 2014 Fev 10];14(1):189-96. Disponível em: https:// www.fen.ufg.br/revista/v14/n1/pdf/v14n1a22.pdf.

12. Taddeo PS, Gomes KWL, Caprara A, Gomes AMA, Oliveira GC, Moreira TM. Acesso, prática educativa e empoderamento de pacientes com doenças crônicas. Rev Ciênc Saúde Coletiva. 2012;17(11):2923-30.

13. Canesqui AM, organizador. Adoecimentos e sofrimentos de longa duração. $2^{\mathrm{a}}$ ed. São Paulo: Hucitec; 2015.

14. Campos LF, Almeida JZ, Campos FF, Campos LA. Prática alimentar e de atividade física em adolescentes obesos de escolas públicas e privadas. Rev Bras Promoç Saúde. 2014;27(1):92-100.
15. Martins AJ, Cardoso MHCA, Llerena JC Júnior, Moreira MCN. A concepção de família e religiosidade presente nos discursos produzidos por profissionais médicos acerca de crianças com doenças genéticas. Ciênc Saúde Coletiva. 2012;17(2):545-53.

16. Brunner, LS, Suddarth DS. Tratado de enfermagem médico-cirúrgica. 12 ${ }^{\mathrm{a}}$ ed. Rio de Janeiro: Guanabara Koogan; 2012. v. 2.

17. Corrêa A, Franco S, Demário RL, Santos EF. Diabetes mellitus tipo 1: vivência dos pais em relação à alimentação de seu filho. Brazilian Journal of Food\&Nutrition/Alim Nutr. 2012; 23(4):632-7.

18. Molmelstet KC, Fanton S, Silva CRLD, Bertoncini $\mathrm{JH}$, Vargas DM, Campanella LCA. Conhecimento nutricional da equipe multiprofissional que atende usuários com diabetes mellitus em uma unidade básica de saúde de Blumenau-SC. Rev APS. 2016; 19(1): 31-8.

19. Brasil. Decreto $n^{0} 7.508$, de 28 de junho de 2011. Regulamenta a Lei $n^{\circ} 8.080$, de 19 de setembro de 1990, para dispor sobre a organização do Sistema Único de Saúde-SUS, o planejamento da saúde, a assistência à saúde e a articulação interfederativa, e dá outras providências. Diário Oficial da União: Brasília. 2011. [acesso em 2014 Mar 21]. Disponível em: http:// www.planalto.gov.br/ccivil_03/leis/L8080.htm

20. Gerhardt TER, Adriana R, Deise L. Itinerário terapêutico de pacientes com câncer: encontros e desencontros da Atenção Básica à alta complexidade nas redes de cuidado. In: Pinheiro R, Silva AG Júnior, Mattos RA. Atenção básica e integralidade: contribuições para estudos de práticas avaliativas em saúde. Rio de Janeiro: CEPESC; 2011. p. 197-214.

21. Bertin RL, Elizio NPS, Moraes RNT, Medeiros CO, Fiori LS, Ulbrich AZ Percepções do cotidiano alimentar de crianças e adolescentes com diabetes mellitus tipo 1. Rev Contexto \& Saúde. 2016;16(30):100-9.

22. Fialho FA, Dias IMAV, Nascimento L, Motta PN, Pereira SG. Crianças e adolescentes com diabetes mellitus: cuidados/complicações para a enfermagem. Rev Baiana de Enferm. 2011;25(2):145-54.

\author{
Endereço para correspondência: \\ Marinês Finco \\ Universidade Regional de Blumenau - FURB \\ Rua Antônio da Veiga, 140 \\ Bairro: Itoupava Seca \\ CEP: 89012-900 - Blumenau - SC - Brasil \\ E-mail: marines.finc@gmail.com
}

